\title{
Original repair after Ross failure: A case report of bicuspidized unicuspid autograft
}

Veronica Lorenz, MD, Sébastien Gonthier, MD, Jama Jahanyar, MD, PhD, FACS, Laurent de Kerchove, $\mathrm{PhD}$, and Gebrine El Khoury, MD, Brussels, Belgium

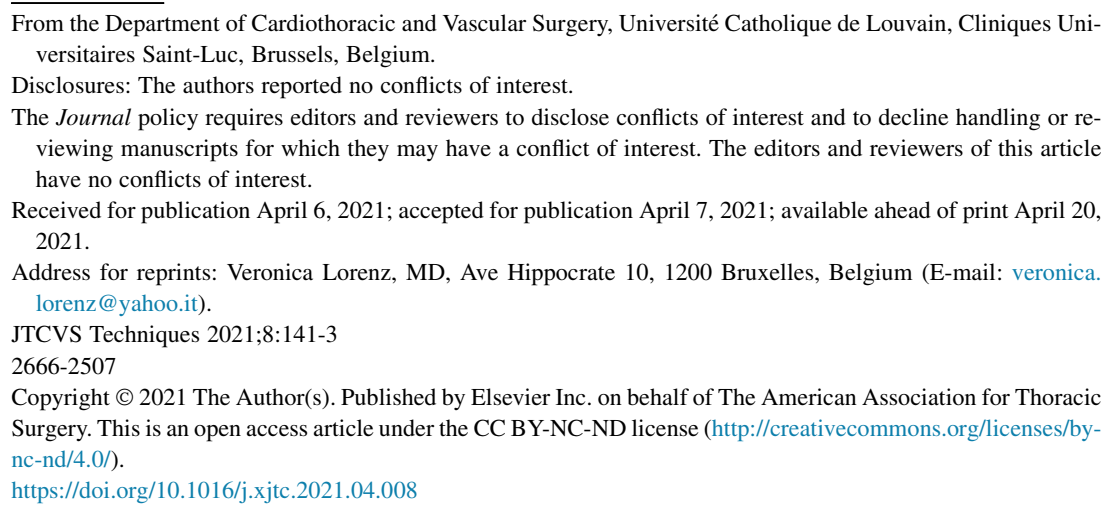

Video clip is available online.

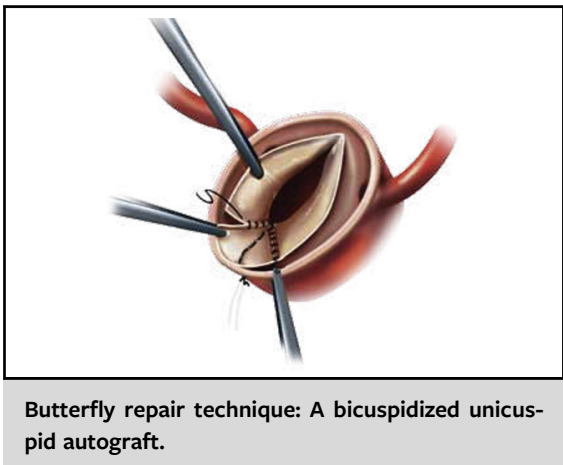

CENTRAL MESSAGE

Repair of failed pulmonary autograft valve after Ross procedure might extend the benefits of the intervention and preserve young patients' quality of life.

\section{CASE REPORT}

A 14-year-old girl with a diagnosis of critical aortic stenosis with hypoplasia of the aortic arch and aortic coarctation underwent balloon valvuloplasty 4 days after birth in another hospital. As a result, she developed severe aortic insufficiency and a Ross procedure was performed at 31 days of life with a 14-mm Contrega conduit (Medtronic, Minneapolis, Minn) to reconstruct the right ventricular outflow tract and pulmonary artery. During the harvesting of the pulmonary autograft, minimal pulmonary valve dysplasia was noted and the pulmonary valve appeared bicuspid with synechia at the commissural level. Nine years after the original operation, the patient underwent a replacement of the Contrega conduit, with a pulmonary homograft, because of structural deterioration.

The patient was then referred to our hospital at age 14 because of the onset of exertional dyspnea and angina. A transthoracic echocardiography revealed an autograft morphologically bicuspid with severe valve stenosis (peak gradient, $97 \mathrm{~mm} \mathrm{Hg}$; aortic valve area, $0.6 \mathrm{~cm}^{2}$ ). The autograft root diameter was calculated at $33 \mathrm{~mm}$ and ascending aorta at $35 \mathrm{~mm}$. The pulmonary homograft appeared thickened with mild insufficiency and a peak gradient of $19 \mathrm{~mm} \mathrm{Hg}$.

\section{SURGICAL TECHNIQUE}

As illustrated in Figure 1, after redo sternotomy, cardiopulmonary bypass was established via the ascending aorta and right atrium. The aorta was crossclamped and antegrade intermittent blood cardioplegia was delivered into the root to achieve cardiac arrest. Following aortotomy, valve analysis revealed a severely stenotic unicuspid valve. The anterior commissure was normally developed to the sinotubular junction but fused for a few millimeters, whereas the posterior commissure (first raphe) was completely fused, fibrotic, and with a lower level of attachment. The second raphe was localized between left and noncoronary cusps. After commissurotomy of the 2 commissures, minimal shaving of the leaflets was performed to excise the thickened portions. A decision was made to use a decellularized equine pericardial patch (Matrix Patch; Auto Tissue, Berlin, Germany) to bicuspidize the autograft valve. The patch was implanted using the butterfly technique to reconstruct a functional posterior commissure at $180^{\circ}$ of the opposite one and creating 2 symmetric cusps with good mobility (Figure 2 ). ${ }^{1}$ The previous pulmonary homograft was replaced with a new homograft because of concerns of beginning degeneration. The duration of cardiopulmonary bypass was 110 minutes 


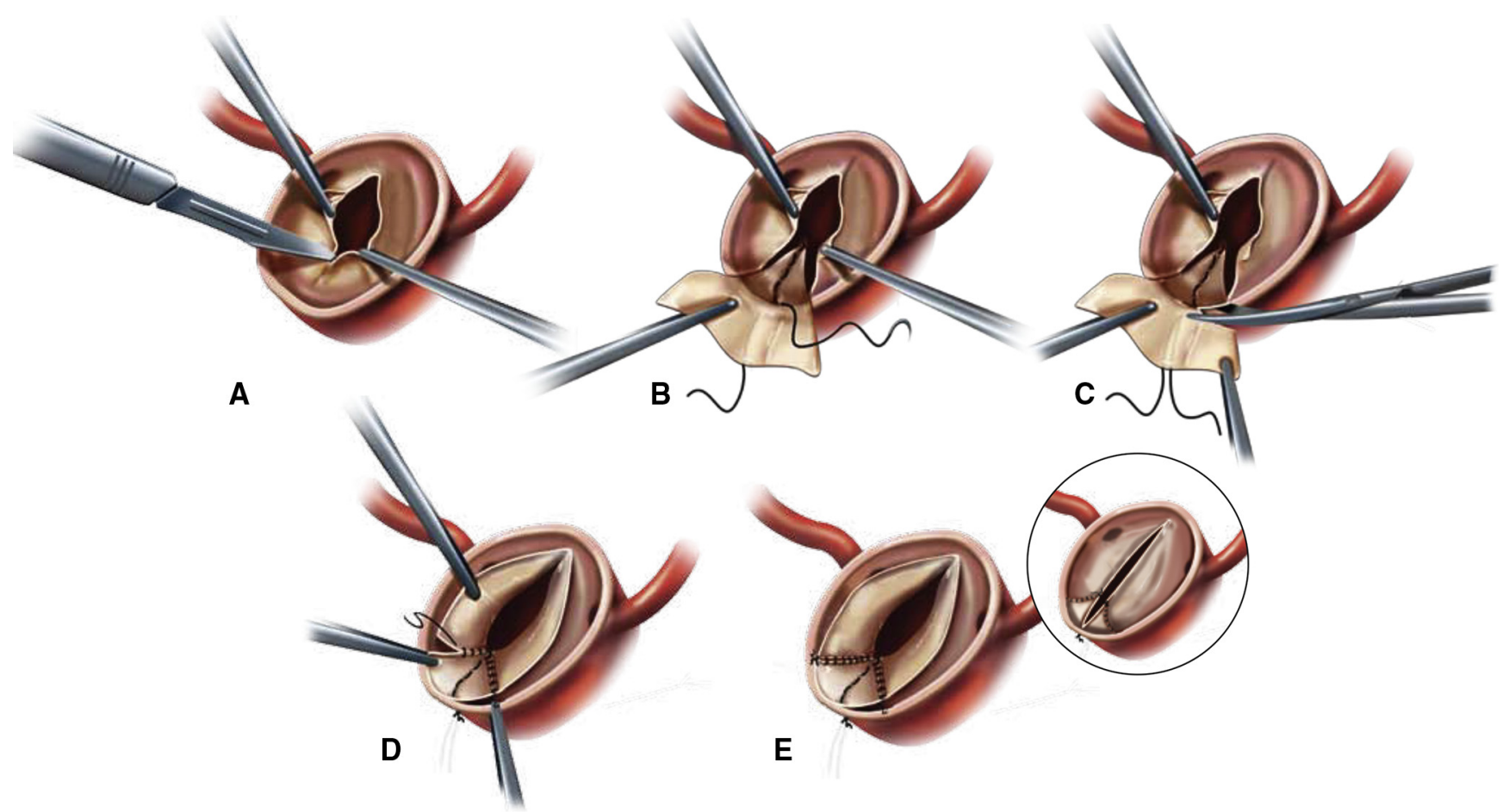

FIGURE 1. The surgical steps to transform a unicuspid autograft into a symmetric bicuspid valve. A, Division of the raphe, to create a new Commissure. B, Anchoring of an autologous pericardial patch to the aortic wall, midline to the neo-commissure from virtual basal ring to sinotubular junction. C, Trimming of the patch. D, Suturing of the patch to the 2 leaflets edges. E, Final result of the butterfly patch in open and nearly closed position.

with 90 minutes of crossclamp time. Intraoperative echocardiography showed a symmetric bicuspid aortic valve with trivial insufficiency at the level of the anterior commissure and good cusps mobility with peak gradient of $14 \mathrm{~mm} \mathrm{Hg}$. The patient was extubated on day 0 and had an uneventful postoperative course being discharged on postoperative day 7.

Three months after surgery, the patient was in optimal clinical condition, not complaining of chest pain or dyspnea, and returned to her daily activities. Follow-up echocardiography showed correct function of the aortic autograft with trivial insufficiency with a peak gradient of $12 \mathrm{~mm} \mathrm{Hg}$. Left and right ventricles were normal for function and diameter; mild pulmonary insufficiency was detected with a peak gradient of $10 \mathrm{~mm} \mathrm{Hg}$. The entire process has been documented in the Video 1 .

\section{DISCUSSION}

The Ross procedure is an established option for aortic valve diseases and complex left ventricular outflow tract obstructions in children and young adult because it offers excellent hemodynamic parameters, low risk of endocarditis, and avoidance of lifelong anticoagulation therapy. ${ }^{2}$ Moreover, the pulmonary autograft respects somatic growth through the years, whereas aortic valve replacement is generally not recommended in children due to progressive mismatch between the growing patient and the prosthesis.

However, cardiac reoperations are not infrequent in pediatric populations because of structural deterioration of the pulmonary homograft or dilation and valve regurgitation of the autograft. Studies confirmed that despite the technical challenge, reoperation following Ross procedure can be performed with low mortality and good midterm results. ${ }^{3}$

As previously shown, the same techniques for aortic valve repair could also be successfully applied to a dysfunctional pulmonary autograft after Ross procedure. ${ }^{4}$ In this regard, restoration of valve symmetry, cusp orientation, and functional root anatomy is paramount. In the case of unicuspid aortic valve, Matsushima and colleagues ${ }^{5}$ from Homburg/Saar, Germany, and others have shown that symmetric bicuspidization in unicuspid valve is a reliable technique with good long-term outcomes.

We therefore opted for a surgical repair of the unicuspid autograft considering that an alternative management with subsequent percutaneous procedures of balloon valvuloplasty in this patient would have not only impaired her quality of life but also damaged the native valve requiring a further mechanical valve replacement. Conversely, the possibility to restore the autograft valve function, guarantees her the avoidance of anticoagulation and the possibility of future pregnancies. 

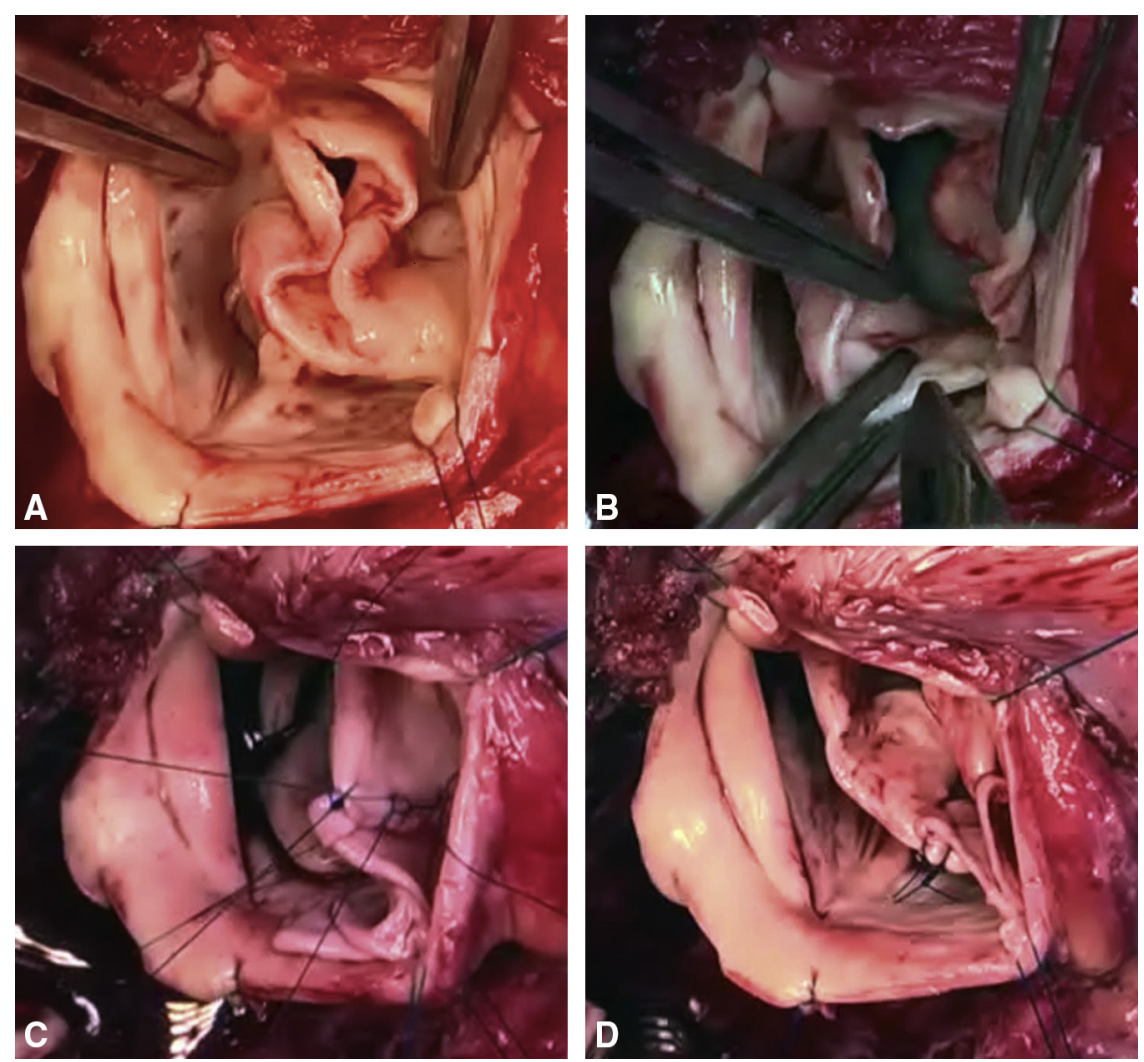

FIGURE 2. A, Unicuspid autograft, with 1 well developed but fused Commissure and 2 raphes. B, Division of posterior raphe. C, Suturing of patch to valve leaflets, after anchoring of patch to the aortic wall. D, Final results of butterfly patch technique.

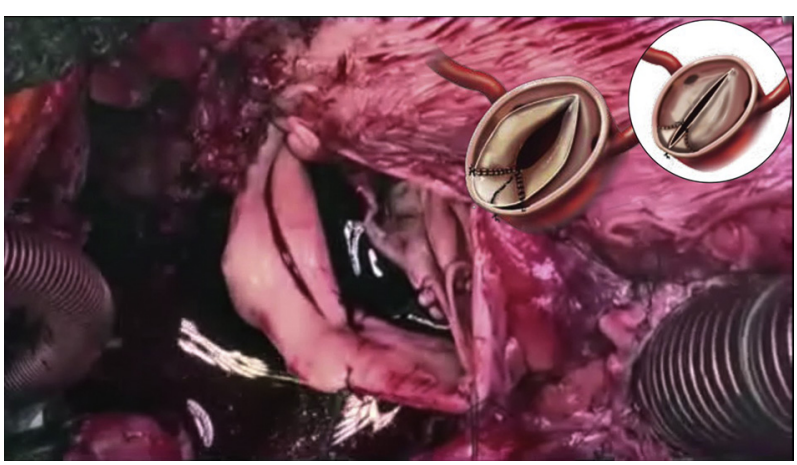

VIDEO 1. The video presents a neo-aortic valve repair through bicuspidization of a unicuspid valve following a Ross procedure. The video shows the surgical steps of valve repair and the use of butterfly patch technique to create the new commissure and bicuspidize unicuspid neo aortic valve. The follow-up echocardiogram after 3 months shows good autograft a neoaortic valve function. Video available at: https://www.jtcvs.org/article/S26662507(21)00300-X/fulltext.
This successful experience suggests that even in the case of degenerated unicuspid aortic autograft, valve repair is feasible applying anatomic principles normally used for aortic valve repair. Indeed, bicuspidization with the use of pericardial patch can be a valid technique to restore the normal motion and create a large surface of coaptation.

\section{References}

1. Vohra HA, de Kerchove L, Rubay J, El Khoury G. A simple technique of commissural reconstruction in aortic valve-sparing surgery. J Thorac Cardiovasc Surg. 2013;145:882-6.

2. Misfeld M, Borger MA. The Ross procedure: time to reevaluate the guidelines. $J$ Thorac Cardiovasc Surg. 2019;157:211-2.

3. Mookhoek A, de Kerchove L, El Khoury G, Weimar T, Luciani GB, Mazzucco A et al. European multicenter experience with valve-sparing reoperations after the Ross procedure. J Thorac Cardiovasc Surg. 2015;150:1132-7.

4. de Kerchove L, Boodhwani M, Etienne PY, Poncelet A, Glineur D, Noirhomme P, et al. Preservation of the pulmonary autograft after failure of the Ross procedure. Eur J Cardiothorac Surg. 2010;38:326-32.

5. Matsushima S, Heß A, Lämmerzahl JR, Karliova I, Abdul-Khaliq H, Schäfers HJ Unicuspid aortic valve repair with bicuspidization in the paediatric population. Eur J Cardiothorac Surg. 2021;59:253-61. 